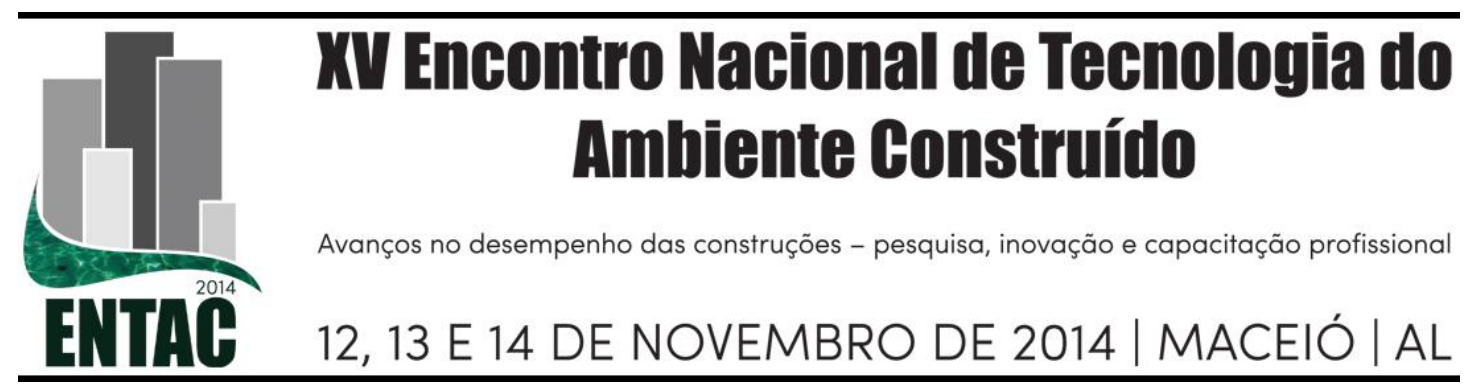

\title{
ESTUDO DA ESTRUTURA POROSA DE ARGAMASSAS DE REVESTIMENTOS A PARTIR DE ENSAIOS DE CAPILARIDADE E MICROSCOPIAS
}

\author{
SALOMÃO, Maria Cláudia (1); BAUER, Elton (2)
}

(1) Universidade de Brasília, e-mail: mariacsalomao@ hotmail.com (2) Universidade de Brasília, e-mail: elbauerlem@gmail.com,

\begin{abstract}
RESUMO
Os revestimentos argamassados são higroscópicos e sofrem influência da umidade presente no ar ou advinda de uma fonte como o contato com solo úmido ou pontos de infiltração. A facilidade de entrada da água dentro dos poros pode ser influenciada pela composição da argamassa (proporção entre os materiais constituintes), e alterada pela presença de aditivos, principalmente daqueles com ação hidrofugante. Este trabalho é a parte experimental inicial de uma tese de doutorado e tem como objetivo observar o comportamento de diferentes argamassas, com e sem a presença de aditivos. A metodologia experimental deste estudo propõe a avaliação das argamassas de revestimento produzidas em laboratório com diferentes teores de estearato de cálcio. O comportamento das argamassas foi avaliado a partir de ensaios de capilaridade e interpretação da microestrutura por meio de microscopia eletrônica de varredura. Os resultados obtidos nos ensaios de absorção por capilaridade evidenciam a diferença de comportamento das argamassas. Aquelas produzidas sem aditivos apresentaram coeficiente de capilaridade consideravelmente maior que aquelas produzidas com estearato de Cálcio. As microscopias eletrônicas de varredura ressaltaram a diferença de rugosidade nos poros das argamassas. Observou-se que os poros das argamassas aditivadas contém material impregnado em sua superfície, enquanto os poros das argamassas sem aditivos são lisos.
\end{abstract}

Palavras-chave: hidrofugantes, capilaridade, argamassa de revestimento.

\begin{abstract}
Rendering mortars are hygroscopic materials and influenced by the moisture present in the air or rising from a source such as soil moisture or infiltration. The ease of entry of water into the pores can be influenced by the composition of the mortar (ratio between the constituent materials), and amended by the presence of additives, especially those with repellent action. This work is the initial part of an experimental thesis and aims to observe the behavior of a number of mortars produced with and without additives. The experimental methodology of this study proposes the evaluation of rendering mortars produced in laboratory with different concentrations of calcium stearate. Mortars behavior was evaluated from capillary tests and interpretation of the microstructure by scanning electron microscopy. Results showed great difference between the mortars. Those produced without additives show considerably higher capillarity coefficient than those produced with calcium stearat. The electronic scanning microscopy highlighted the difference in roughness of mortars pores. It was observed that additivated mortars had a impregnated material on their pore surface, while the pores of mortar without any additives are smoother .
\end{abstract}

Keywords: hidrofugantes, capilaridade, argamassa de revestimento. 


\section{INTRODUÇÃ̃o}

Os revestimentos argamassados são higroscópicos e sofrem influência da umidade presente no ar ou advinda de uma fonte como o contato com solo úmido ou pontos de infiltração.

A movimentação de água pelos capilares de argamassas pode ser estudada pela análise da estrutura porosa desses materiais. A facilidade de entrada da água dentro dos poros pode ser influenciada pela composição da argamassa (proporção entre os materiais constituintes), e alterada pela presença de aditivos, principalmente daqueles com ação hidrofugante.

Os mais variados produtos de ação impermeabilizantes disponíveis no mercado são comercializados sem que suas propriedades sejam informadas. Dafico et al (2004) ressaltam que os catálogos técnicos normalmente apresentam poucas informações, na maioria das vezes irrelevantes, enquanto que as informações realmente importantes, tais como, a composição química ou o mecanismo de ação, são quase sempre inexistentes.

Binda et al (1999) concluíram que com todas as técnicas de investigação disponíveis, as avaliações normalmente se baseiam na medida indireta da eficiência e durabilidade através do controle da umidade na superfície, na absorção de água ou temperatura.

Isso significa que ainda existe um grande número de questionamentos sobre como os diversos tipos de aditivos modificam o desempenho das mais variadas composições de argamassas.

Este trabalho é a parte experimental inicial de uma tese de doutorado, e tem como objetivo observar o comportamento frente à umidade de diferentes argamassas, com e sem a presença de aditivos.

\section{PRODUTOS QUE ALTERAM O TRANSPORTE DE ÁGUA EM ARGAMASSAS}

Uma alternativa para a proteção de edificações contra a ação da umidade é a mistura de agentes hidrofugantes na própria argamassa. Esses aditivos podem ser de composição variada sendo mais recorrentes os sabões metálicos e os silicones em pó, além de outros materiais produzidos a partir de polímeros sintéticos.

Os sabões metálicos são sais de ácidos graxos de cadeia longa, como o estearato de cálcio, estearato de zinco e oleato de sódio. Esses produtos são caracterizados por uma longa cadeia apolar de hidrocarbonetos e um grupo polar em uma ponta (Figura 1), ou seja, são produtos de natureza bipolar. Tanto os esteratos quanto os oleatos são comercializados como aditivos impermeabilizantes devido à eficiência alcançada e baixo custo (LANZÓN; GARCÍA-RUIZ, 2009).

Figura 1 -- Estrutura química do (a) Ácido estearico, $\mathrm{Mn}+=\mathrm{Zn2}+$ ou $\mathrm{Ca} 2+$ (b) Oleato de sódio.

(a)

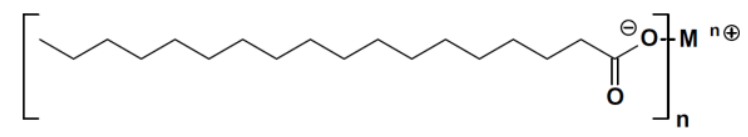

(b)

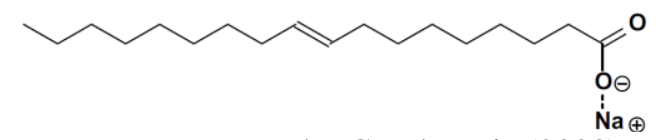

Fonte: Lanzón; García-Ruiz (2008) 
Com a finalidade de testar a eficiência desses agentes impermeabilizantes, Lanzón e García-Ruiz (2009) submeteram argamassas de cimento com diferentes dosagens de aditivos a ensaios de absorção.

Dentre os sabões, o oleato de sódio foi considerado a melhor alternativa de hidrorepelente. As argamassas com estearato de zinco foram eficientes, mas somente apresentam absorção capilar equiparada ao do oleato para dosagens acima de 1,00\%. Já aquelas dosadas com estearato de cálcio, o desempenho foi insatisfatório para dosagens abaixo de $1,00 \%$ pois ultrapassa o limite de $0,4 \mathrm{~kg} / \mathrm{m}^{2} \mathrm{~min}^{0,5}$ estipulado pela EN 998-1.

Em outro trabalho de Lanzón e García-Ruiz (2008), foi analisado o comportamento, quanto à durabilidade e impermeabilidade, de argamassas com a adição de estearato de zinco, estearato de cálcio, oleato de sódio e silicone em pó. Neste estudo, foi observado que o estearato de cálcio e o estearato de zinco não mostram alta impermeabilidade em argamassas de pequenas idades (7 dias). Dessa forma, esses produtos não devem ser recomendados para argamassas que serão expostas a frequentes ou fortes chuvas nos primeiros dias após a aplicação.

Quanto à diferença de desempenho entre os dois tipos de sabão, o mesmo tipo de comportamento que aponta melhores resultados em argamassas com adição de oleatos também foi observado por Izaguirre et al (2009). Uma possível explicação para a melhor performance do oleato é o fato dos estearatos serem insolúveis em água, enquanto o oleato é solúvel em água.

Assim, entende-se que a dispersão do oleato durante o processo de mistura é mais eficiente. Além disso, Lanzón et al (2011) observaram que, em misturas ricas em filler calcário, o oleato de sódio reage na superfície do filler originando o oleato de cálcio. Esse processo forma uma camada insolúvel, quimicamente absorvida na superfície do filler, que pode explicar a alta atividade repelente dessa adição.

Ainda no estudo dos sabões metálicos, Wang et al (2006) apontaram que o estearato de sódio produzido a partir da saponificação do ácido esteárico com o $\mathrm{NaOH}$ induz a nucleação e crescimento do carbonato de cálcio. E quanto à ação do produto, foi apontado que o estearato de sódio modifica as características da superfície do carbonato de cálcio, tornando-o hidrofóbico.

Izaguirre et al (2009) também buscou estudar o mecanismo que confere propriedades hidrofugantes em argamassas com adição desses sabões. Para tal foram realizados ensaios de capilaridade, permeabilidade ao vapor, porosimetria por intrusão de mercúrio além de microscopias. Os resultados indicaram que argamassas com estearato ou oleato apresentam reduzidos coeficientes de capilaridade. Porém, para as mesmas argamassas a permeabilidade ao vapor é maior que na argamassa referencia.

A partir desses dados, Izaguirre et al (2009) endossaram a teoria que o estearato e o oleato trabalham como tensoativos aniônicos e por isso podem incorporar ar à mistura. Ou seja, por serem bipolares, eles são capazes de serem absorvidos e concentrados na interface pasta/ar, estabilizando os poros de ar, como incorporadores de ar.

Dessa forma, esses produtos podem modificar a distribuição de tamanho de poros na argamassa, de maneira que ocorra uma diminuição no número de poros grandes e um aumento na quantidade de microporos. Assim, a movimentação de água pelos capilares seria bloqueada pela presença de bolhas de ar (IZAGUIRRE et al, 2009) 


\section{MATERIAIS E MÉTODOS}

A metodologia experimental deste estudo propõe a avaliação das argamassas de revestimento produzidas em laboratório com diferentes teores de estearato de cálcio. Essas argamassas se diferenciam pela composição sendo a argamassa referência, denominada REF, constituída apenas cimento, cal e areia. Já as argamassas denominadas $\mathrm{CaS}$ 0,25 e CaS 1,00, além dos constituintes básicos foram acrescidas de Estearato de cálcio nos teores de $0,25 \%$ e $1,00 \%$, respectivamente, sobre a massa de material seco.

O traço adotado para as argamassas foi de 1:1:6 em volume. Os materiais utilizados foram o cimento CPV, a cal CHI e areia natural. A caracterização dos materiais é apresentada na Tabela 1.

\section{Tabela 1 - Composição das argamassas ensaiadas}

\begin{tabular}{|c|c|c|}
\hline Material & Massa específica $\left(\mathbf{g} / \mathbf{c m}^{3}\right)$ & Massa unitária $\left(\mathbf{g} / \mathbf{c m}^{\mathbf{3}}\right)$ \\
\hline Cimento & 3,10 & 1,00 \\
\hline Cal & 1,98 & 0,50 \\
\hline Areia & 2,64 & 1,57 \\
\hline Estearato de Cálcio & 1,30 & - \\
\hline
\end{tabular}

O comportamento das argamassas foi avaliado a partir de ensaios de capilaridade e interpretação da microestrutura por meio de microscopia eletrônica de varredura.

\subsection{Ensaio de absorção por capilaridade}

O ensaio de absorção por capilaridade foi realizado segundo as prescrições da NBR 15259 (ABNT,2005). O ensaio foi realizado 28 dias após a moldagem dos corpos de prova prismáticos.

Após o ensaio os corpos de prova foram mantidos em ambiente de laboratório, com umidade e temperatura estáveis, até a constância de massa e submetidos novamente ao ensaio de capilaridade.

Esse processo foi repetido 5 vezes, nos mesmos exemplares, com o intuito de avaliar a eficiência dos produtos impermeabilizantes ao longo do tempo. Essa avaliação foi feita a partir da quantidade de água absorvida nos ensaios de capilaridade, da quantidade de água residual após a secagem e do coeficiente de capilaridade após os repetidos ciclos.

\subsection{Microscopia eletrônica de varredura}

A microscopia eletrônica de varredura foi utilizada para se correlacionar a microestrutura de um material com seu comportamento e composição.

A análise foi realizada no Laboratório de Geocronologia do Instituto de Geociência da Universidade de Brasília.

A preparação das amostras para o ensaio foi feita cortando corpos de prova cilíndricos nas dimensões aproximadas de $2 \mathrm{~cm} X \quad 2 \mathrm{~cm} \mathrm{X} 1 \mathrm{~cm}$ (largura $X$ comprimento $X$ espessura). As amostras foram secas em estufa a $100^{\circ} \mathrm{C}$ e armazenadas em recipiente com sílica gel e antes do início do ensaio foram impregnadas com uma camada de carbono

As imagens foram tratadas com o aparelho ajustado no modo baixo vácuo, conforme indicado em por Lanzón et al (2011). 


\section{RESULTADOS}

As argamassas produzidas foram caracterizadas no estado fresco quanto à profundidade de penetração de cone, teor de ar incorporado e retenção de água. A Tabela 2 apresenta os resultados desses ensaios. Observa-se que a adição do Estearato de Cálcio nos teores de $0,25 \%$ e $1,00 \%$ não afetou as propriedades das argamassas no estado fresco.

Tabela 2 - Propriedades das argamassas no estado fresco.

\begin{tabular}{|c|c|c|c|}
\hline Argamassa & Cone (mm) & Teor de ar incorporado (\%) & Retenção de água $(\boldsymbol{\%})$ \\
\hline $\mathrm{REF}$ & 56 & 4 & 75 \\
\hline $\mathrm{CaS} 0,25$ & 53 & 4 & 76 \\
\hline $\mathrm{CaS} 1,00$ & 55 & 4 & 79 \\
\hline
\end{tabular}

Já no estado endurecido, os corpos de prova foram ensaiados 28 dias após a moldagem. Observa-se pelos dados apresentados na Tabela 3 que o acréscimo do aditivo resultou em um pequeno aumento dos valores de resistência à compressão e à tração.

Tabela 3 - Propriedades mecânicas das argamassas.

\begin{tabular}{|c|c|c|c|}
\hline Argamassa & $\begin{array}{c}\text { Relação } \\
\text { água/materiais secos }\end{array}$ & $\begin{array}{c}\text { Resistência à compressão } \\
\text { aos 28 dias (MPa) }\end{array}$ & $\begin{array}{c}\text { Resistência à tração na } \\
\text { flexão aos 28 dias (MPa) }\end{array}$ \\
\hline REF & 0,184 & 4,5 & 1,5 \\
\hline $\mathrm{CaS} 0,25$ & 0,189 & 4,9 & 1,7 \\
\hline $\mathrm{CaS} 1,00$ & 0,186 & 5,6 & 1,8 \\
\hline
\end{tabular}

\subsection{Ensaio de Absorção por capilaridade}

As Figuras 2 e 3 permitem avaliar a quantidade de água absorvida no ensaio de capilaridade. Observa-se que ao longo de todas as repetições, a quantidade de água absorvida pela argamassa referência foi invariavelmente superior à quantidade de água absorvida pelas argamassas com aditivos.

Figura 2 - Absorção de água por capilaridade calculada para cada tempo. As curvas de cores semelhantes representam a mesma argamassa em ensaios diferentes.

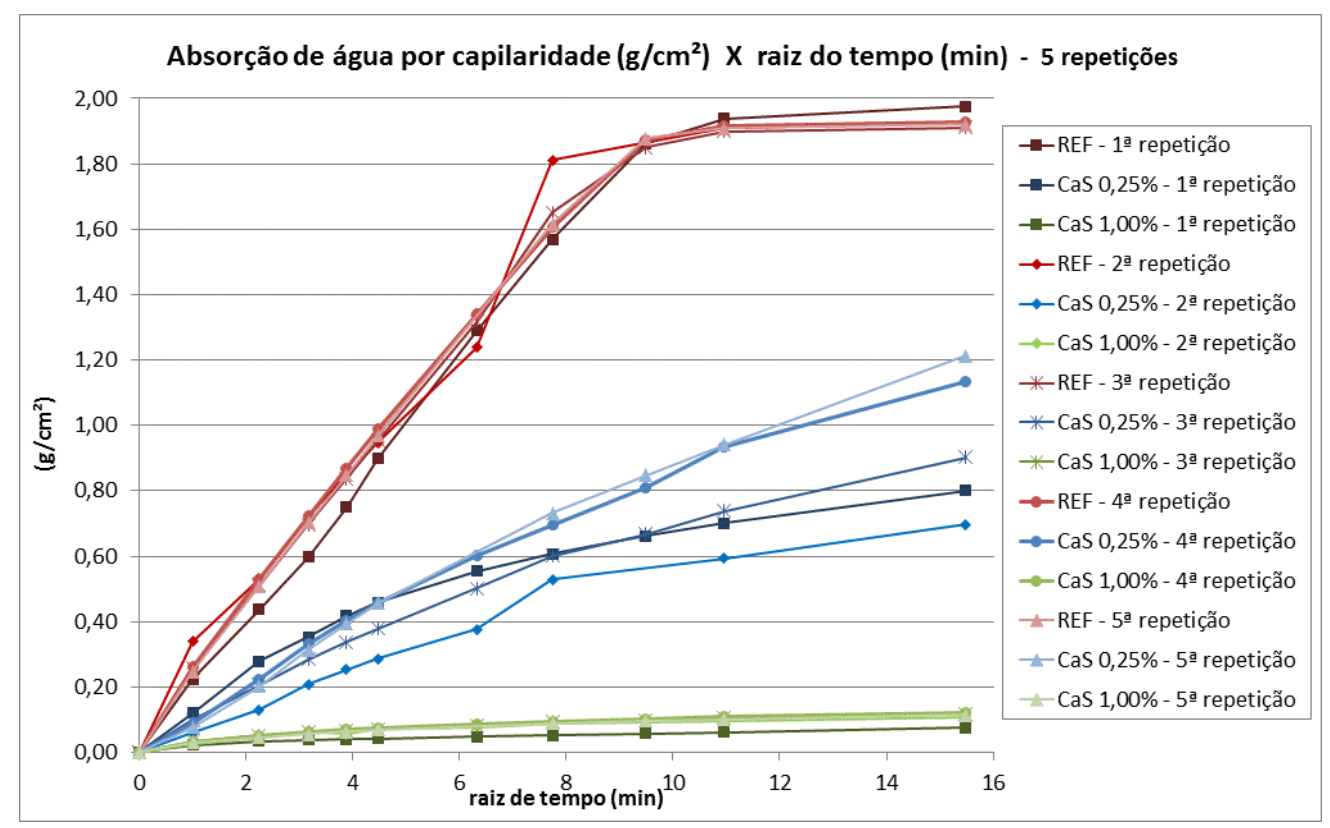


Entre as argamassas com aditivo, aquela com teor de 1,00\% de Estearato de Cálcio foi a argamassa que se mostrou mais eficiente. Observa-se ainda que, comparando as cinco repetições, a argamassa com $0,25 \%$ de estearato de cálcio apresentou maior variação de quantidade de água absorvida nos diferentes ensaios. Essa variação não foi observada na argamassa Referência e na argamassa com 1,00\% de Estearato de Cálcio.

A Tabela 4 apresenta os mesmos dados da Figura 8 calculados na forma de Coeficientes de Capilaridade. É possível observar a diferença entre os Coeficientes de Capilaridade das argamassas. A argamassa com 1,00\% de Estearato de Cálcio manteve baixos valores ao longo das repetições, entre 0,3 e $0,6 \mathrm{~g} / \mathrm{dm}^{2} \cdot \mathrm{min}^{1 / 2}$. Já no ensaio com a argamassa referência, os valores variaram entre $20,2 \mathrm{e} 18,4 \mathrm{~g} / \mathrm{dm}^{2} \cdot \mathrm{min}^{1 / 2}$.

Tabela 4 - Coeficiente de Capilaridade ao longo das 5 repetições do ensaio.

\begin{tabular}{|c|c|c|c|c|c|}
\hline \multirow{2}{*}{ Argamassa } & \multicolumn{5}{|c|}{ Coeficiente De Capilaridade $\left(\mathbf{g}_{\mathbf{d m}} \mathbf{. m i n}^{\mathbf{1}} \mathbf{2}\right.$} \\
\cline { 2 - 6 } & $\mathbf{1}^{\mathbf{0}}$ ciclo & $\mathbf{2}^{\mathbf{o}}$ ciclo* & $\mathbf{3}^{\mathbf{o}}$ ciclo & $\mathbf{4}^{\mathbf{0}}$ ciclo & $\mathbf{5}^{\mathbf{o}}$ ciclo \\
\hline $\mathrm{REF}$ & 20,2 & - & 18,7 & 18,4 & 18,8 \\
\hline $\mathrm{CaS} 0,25 \%$ & 4,9 & - & 6,1 & 7,6 & 8,6 \\
\hline $\mathrm{CaS} 1,00 \%$ & 0,3 & - & 0,6 & 0,6 & 0,6 \\
\hline
\end{tabular}

* Não foram realizadas as leituras de 90 min para cálculo do Coeficiente de Capilaridade

A Figura 3 representa a variação da massa do corpo de prova ensaio devido à absorção de água no ensaio de capilaridade e perda de água absorvida durante a secagem. Cada pico representa o fim de uma etapa de molhagem e início de uma etapa de secagem. No eixo das abscissas cada evento (medição) é representado por um ponto mas não há escala de tempo.

A observação da Figura 3 corrobora com as análises feitas sobre a Figura 2. A argamassa Referência é a que mais absorve água durante a molhagem, seguida da argamassa com $0,25 \%$ e da argamassa com $1,00 \%$ de Estearato de Cálcio, esta última apresentou o melhor desempenho.

Figura 3 - Representação do ganho de massa e perda de massa devido à absorção e evaporação de água ao longo da molhagem e secagem.

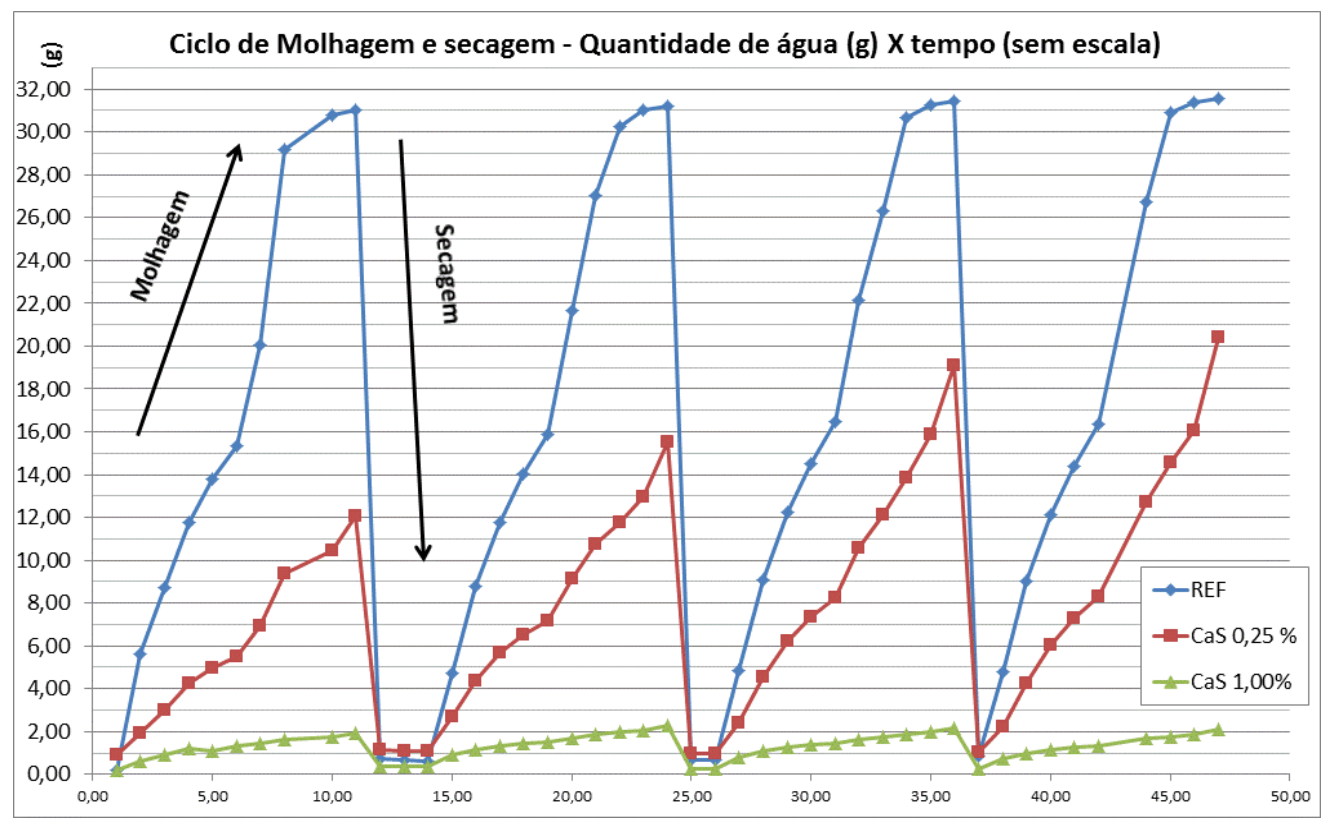


Os dados ilustrados na Figura 3 permitem ainda explorar a eficiência do Estearato de Cálcio ao longo do tempo. Observa-se que a argamassa Referência ao fim do período de secagem não retorna ao estado inicial de secagem, ou seja, não há a repetição da leitura 0 gramas. Desta forma, entende-se que, mesmo permanecendo em ambiente de temperatura e umidade controladas, uma parte da água absorvida permanece nos poros dos corpos de prova.

O comportamento das argamassas com Estearato de Cálcio na secagem é mais eficiente do que o apresentado pela argamassa Referência: a quantidade de "água residual" é menor. Esse comportamento permite extrapolar os resultados e indicar uma maior durabilidade dos revestimentos produzidos com argamassas aditivadas.

\subsection{Microscopia eletrônica de varredura}

A interpretação da morfologia das argamassas se deu através da análise de poros nas seções das amostras. A escolha de se analisar os poros se deu em razão de algumas referências que indicam que a ação do estearato se dá na interface matriz/ar das argamassas ( IZAGUIRRE et al, 2009 e WANG et al, 2006).

Buscou-se identificar nas amostras poros esféricos que representariam poros de ar incorporado na mistura. Quando possível, as imagens foram feitas com a mesma aproximação para facilitar a comparação entre os diferentes tipos de argamassas. Nesses poros, foi analisada a diferença de morfologia dos elementos visualizados.

Nas Figuras 4, 5 e 6 estão apresentados uma região com presença de poro nas argamassas Referência, CaS 0,25 e CaS 1,00, respectivamente.

O poro apresentado na Figura 4 apresenta pequenas fissuras e pouco material precipitado. A superfície do poro é bastante lisa indicando que, após a formação do poro, não houve acúmulo de produto inerte ou mesmo reação dos aglomerantes nessa região.

Figura 4 - Visualização de poro em uma amostra da argamassa referência. Imagem obtida por elétrons secundários, com aproximação de a) 389X e b) $655 \mathrm{X}$

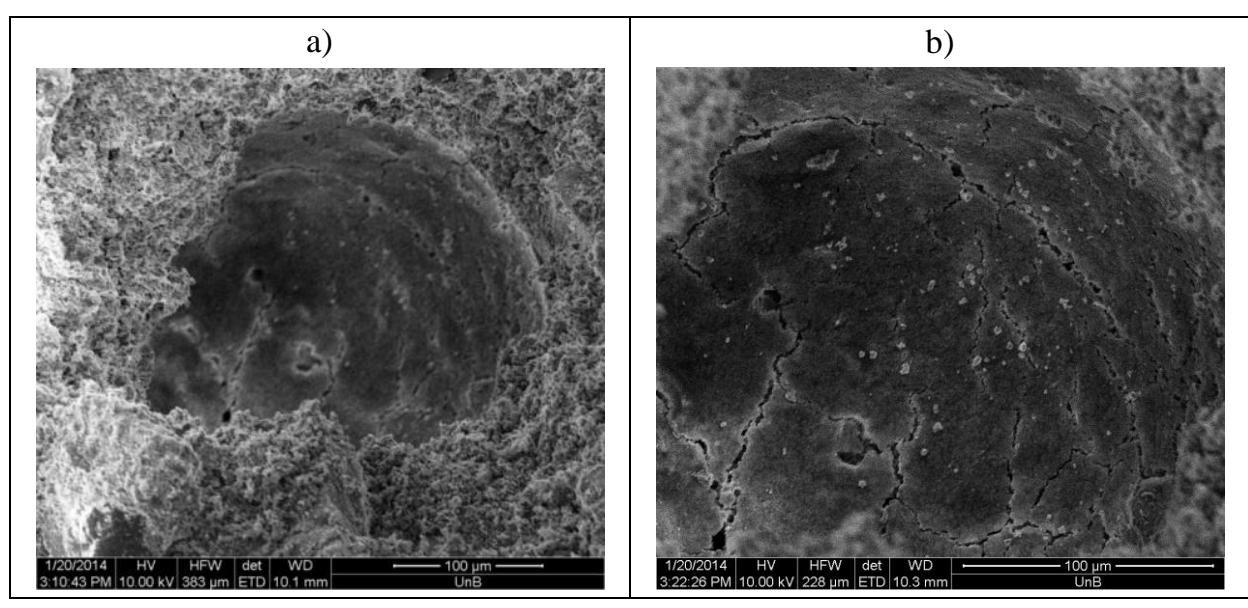

Já nos poros selecionados para análise nas argamassas $\mathrm{CaS} 0,25$ e $\mathrm{CaS}$ 1,00, foi constatado a presença de produtos de forma irregular e elevada superfície específica aderidos à superfície dos poros (Figura 5 e Figura 6). Por meio da interpretação das imagens com aproximação de 2000X é observado que na argamassa com maior teor de estearato a camada aderida ao poro é mais densa. 
Figura 5 - Visualização de poro em uma amostra da argamassa CaS 0,25. Imagem obtida por elétrons secundários, com aproximação de a) $400 \mathrm{X}$ e b) $2000 \mathrm{X}$

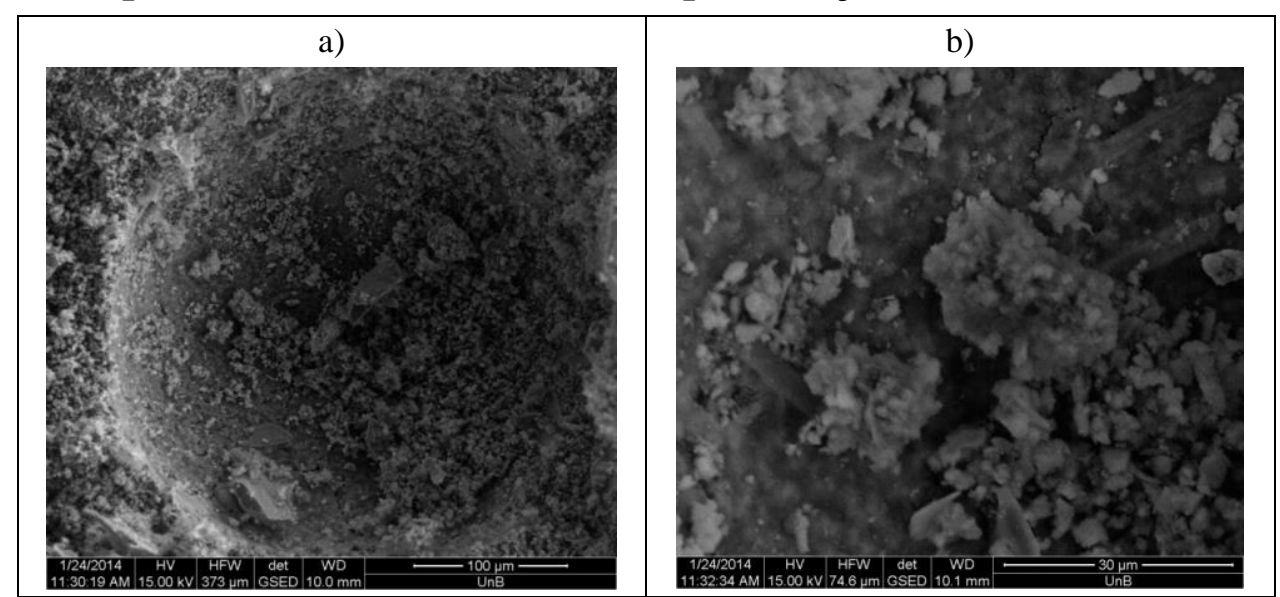

Figura 6 - Visualização de poro em uma amostra da argamassa CaS 1,00. Imagem obtida por elétrons secundários, com aproximação de a) $400 \mathrm{X}$ e b) $2000 \mathrm{X}$

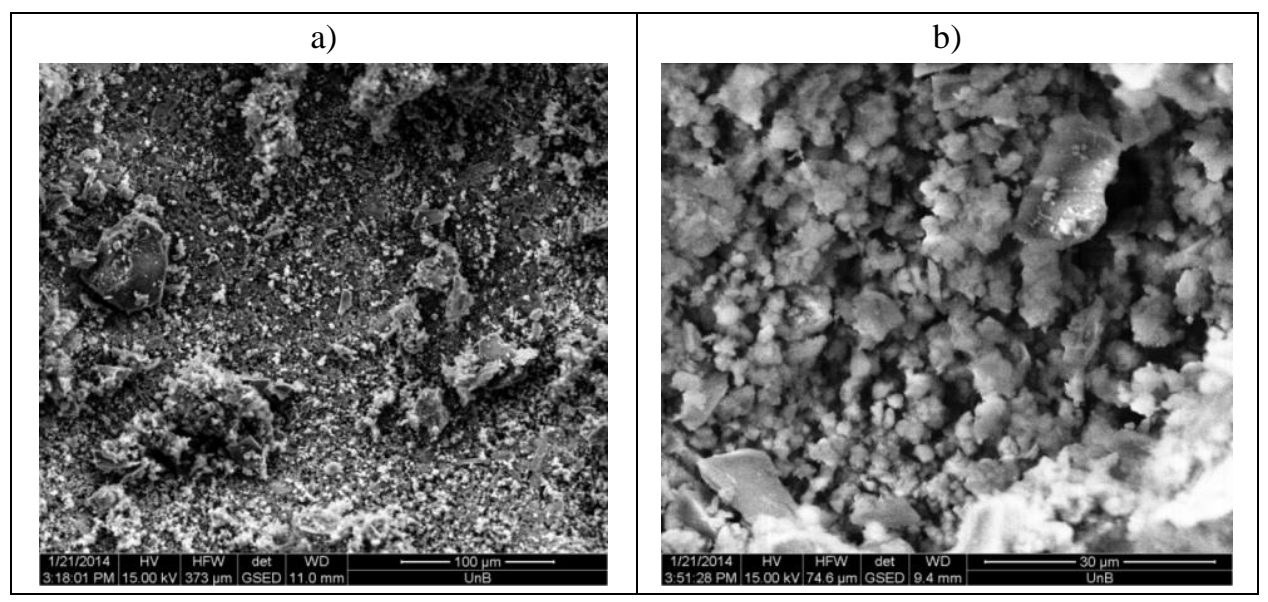

Apesar de Izaguirre et al (2009) ter identificado estearatos em poros de argamassa, a imagem obtida por elétrons retroespalhados não indicaram a presença de constituintes que pudessem indicar a presença de estearato de cálcio (Figura 7).

Figura 7 - Visualização de poro em uma amostra da argamassa a) CaS 0,25 e b)CaS 1,00. Imagem obtida por elétrons retroespalhados, com aproximação de $2000 \mathrm{X}$.

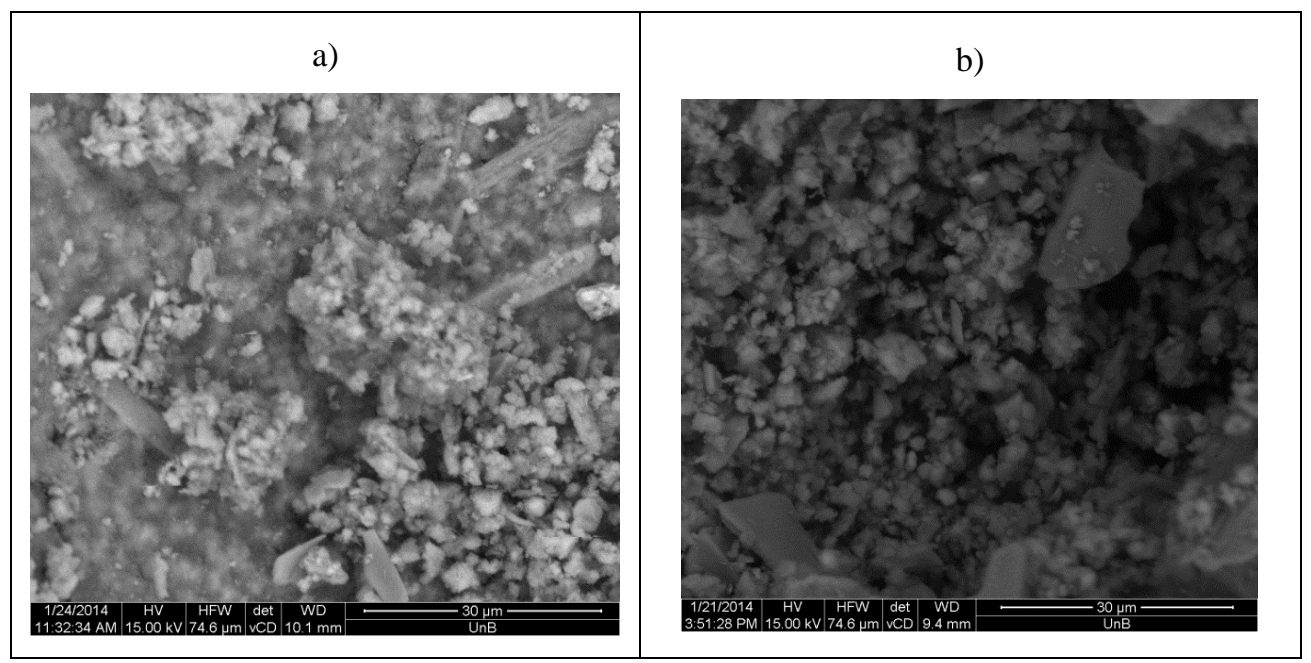


A região escolhida na argamassa CaS 1,00 está representada na Figuras 8. Três pontos foram analisados e em todos eles foi identificada a presença de Silício, Cálcio e Oxigênio. No entanto, na região mais clara, foi observada a presença de Titânio e Cobre.

Como não se pode afirmar que ele reage com algum constituinte da argamassa, formando um produto de composição conhecida, decidiu-se avaliar outras seções das argamassas com estearato a procura da presença de compostos "fora do padrão". Essas formações podem indicar a interação do estearato com algum constituinte ou a presença de "contaminantes" em algum constituinte da argamassa.

As seções escolhidas foram as que apresentaram alguma alteração de escala de cor nas imagens de elétrons retroespalhados. Para cada região estudada foram feitas análises pontuais de EDS que resultou em uma tabela com os elementos (e proporção) em cada ponto analisado.

\section{Figura 8 - Seção analisada por EDS na argamassa CAS 1,0. Imagem obtida por elétrons retroespalhados, no modo baixo vácuo.}

\begin{tabular}{|c|c|c|}
\hline 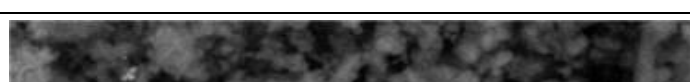 & Elemento & Massa \% \\
\hline & O K & 49.62 \\
\hline & $\mathrm{AlK}$ & 1.66 \\
\hline & $\mathrm{SiK}$ & 13.5 \\
\hline & $\mathrm{CaK}$ & 16.12 \\
\hline 5 & $\mathrm{TiK}$ & 1.07 \\
\hline 802 . & $\mathrm{CuK}$ & 18.03 \\
\hline
\end{tabular}

A região escolhida na argamassa CaS 0,25 está representada nas Figura 9. Nesta área foram analisados 2 pontos que apontaram a presença de Silício, Cálcio, Oxigênio e Alumínio na composição. No entanto, na região mais clara, foi observada ainda a presença de Titânio e Ferro.

Figura 9 - Seção analisada por EDS na argamassa CAS 0,25. Imagem obtida por elétrons retroespalhados, no modo baixo vácuo .

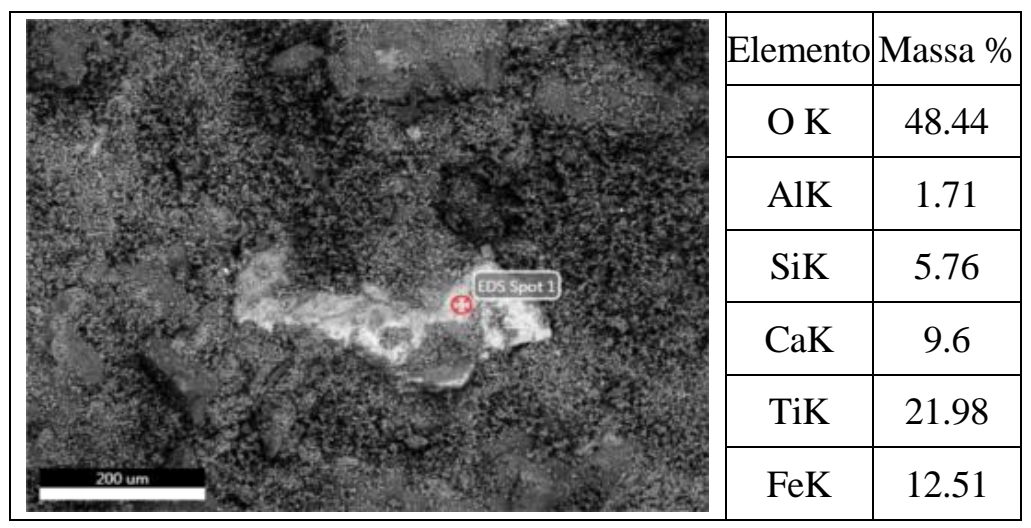




\section{CONCLUSÕES}

Os resultados obtidos nos ensaios de absorção por capilaridade evidenciam a diferença de comportamento das argamassas. Aquelas produzidas sem aditivos apresentaram coeficiente de capilaridade consideravelmente maior que aquelas produzidas com estearato de Cálcio, ou industrializadas.

As microscopias eletrônicas de varredura ressaltaram a diferença de rugosidade nos poros das argamassas. Observou-se que os poros das argamassas aditivadas contém material impregnado em sua superfície, enquanto os poros das argamassas sem aditivos são lisos.

No entanto, conclui-se que ainda não foi possível caracterizar a camada de material aderida aos poros observada nas imagens. Para definir a composição e a formação desses produtos existem algumas ferramentas que serão utilizadas na próxima etapa deste trabalho como a investigação da composição da análise da argamassa via difração raio- $\mathrm{x}$ e fluorescência raio $\mathrm{x}$.

\section{AGRADECIMENTOS}

À CAPES, pelo apoio recebido. Ao Laboratório de Ensaio de Materiais (LEM/UnB) e Laboratório de Geocronologia do Instituto de Geociência da Universidade de Brasília pela disponibilização de técnicos e equipamentos úteis para o desenvolvimento deste trabalho.

\section{REFERÊNCIAS}

ASSOCIAÇÃO BRASILEIRA DE NORMAS TÉCNICAS - ABNT. NBR 15259: Argamassa para assentamento e revestimento de paredes e tetos - Determinação da absorção de água por capilaridade e do coeficiente de capilaridade. Rio de Janeiro, 2005.

BINDA, L.; BARONIO, G.; LUBELLI, B. Evaluation of site control techniques to assess the effectiveness of surface treatments on masonry. Durability of Building Materials and Components, v. 8, 1999.

IZAGUIRRE, A.; LANAS, J.; ÁLVAREZ, J. I. Effect of water-repellent admixtures on the behaviour of aerial lime-based mortars. Cement and Concrete Research, v. 39, n. 11, p. 10951104, 2009.

LANZÓN, M.; GARCÍA-RUIZ, P. A. Effectiveness and durability evaluation of rendering mortars made with metallic soaps and powdered silicone. Construction and Building Materials, v. 22, n. 12, p. 2308-2315, 2008.

LANZÓN, M.; GARCÍA-RUIZ, P. A. Evaluation of capillary water absorption in rendering mortars made with powdered waterproofing additives. Construction and Building Materials, v. 23, p. 3287-3291, 2009.

LANZÓN, M.; GARRIDO, A.; GARCÍA-RUIZ, P. A. Stabilization of sodium oleate as calcium oleate in cement-based mortars made with limestone fillers. Construction and Building Materials, v. 25, n. 2, p. 1001-1008, 2011.

UEMOTO, K. L.; SATO, N. M. N.; JOHN, V. M. Influência do sistema argamassa/ pintura nos fenômenos de transporte de água em revestimentos de argamassas. VII Simpósio Brasileiro de Tecnologia das Argamassas. Anais... , 2007. Recife.

WANG, C.; SHENG, Y.; ZHAO, X.; PAN, Y.; WANG, Z. Synthesis of hydrophobic CaCO3 nanoparticles. Materials Letters, v. 60, n. 6, p. 854-857, 2006. 